\title{
Reaction Time Distributions Across Normal Forgetting: Searching for Markers of Memory Consolidation
}

\author{
Paul J. Reber, ${ }^{1}$ Pablo Alvarez, ${ }^{3}$ and Larry R. Squire ${ }^{1,2,4,5}$ \\ Departments of ${ }^{1}$ Psychiatry and ${ }^{2}$ Neurosciences \\ University of California San Diego School of Medicine \\ La Jolla, California 92093 \\ ${ }^{3}$ Department of Psychology \\ Boston University \\ Boston, Massachusetts 02215 \\ ${ }^{4}$ Department of Veterans Affairs \\ San Diego, California 92161
}

\begin{abstract}
Volunteers studied pictures of objects and were then tested for yes/no recognition at $10 \mathrm{~min}$ and 1 week after learning (experiment 1), or at $10 \mathrm{~min}$ and 4 months after learning (experiment 2). Because the gradual consolidation of long-term memory is thought to occur across this time scale (weeks and months), the reaction time distributions of successfully retrieved items were analyzed in an attempt to detect markers of consolidation. At each retention interval, reaction times for items retrieved successfully were well fit by a model that assumed a single underlying distribution. No evidence for a bimodal distribution of reaction times was observed. Furthermore, there was no evidence that some small subset of items was actually retrieved faster after a long retention interval than after a short interval. The results are consistent with the idea that consolidation works not to increase memory trace strength but to change the nature of memory storage. This process occurs during the course of normal forgetting and may not be observable in the behavior of normal memory.
\end{abstract}

\section{Introduction}

The concept of memory consolidation was

${ }^{5}$ Corresponding author. first proposed in 1900 to account for the phenomenon of retroactive interference in human learning (Muller and Pilzecker 1900). It was pointed out almost immediately that support for consolidation could be found in the facts of temporally graded retrograde amnesia, whereby injury or trauma disrupts memory of recently acquired material (McDougall 1901; Burnham 1903). Ideas about consolidation were subsequently developed in some detail by experimental studies of retrograde amnesia in experimental animals and humans (Russell and Nathan 1946; Glickman 1961; McGaugh and Herz 1972; Squire et al. 1975). The important finding is that after learning is completed, memory can be impaired by convulsive stimulation, pharmacological treatment, or lesion. The magnitude of the impairment is inversely proportional to the learningtreatment interval. That is, memory grows gradually resistant to disruption as time passes after learning.

Different time courses have been discussed under the general concept of consolidation. Disruptive effects of pharmacological manipulations are generally observed when the manipulation occurs within minutes or hours after learning is completed (McGaugh 1989). In contrast, lesion data provide evidence for a gradual, lengthy process by which memories become independent of the medial temporal lobe memory system, a process that may take weeks, months, or even years (Squire and Alvarez 1995). Both of these concepts involve the idea that some manipulation, which is effective at disrupting memory when it is given soon after learning, is ineffective when given at some time later after learning.

LEARNING \& MEMORY 4:284-290 @ 1997 by Cold Spring Harbor Laboratory Press ISSN1072-0502/97 \$5.00

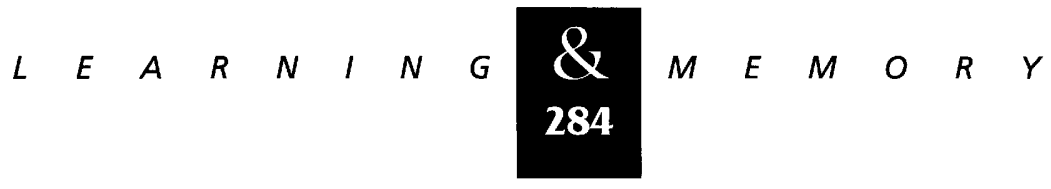


Resistance to disruption can increase at the same time that normal forgetting occurs (Squire et al. 1975; Squire and Spanis 1984). Accordingly, aggregate memory performance must reflect both operations: Memories decay in strength while consolidation is occurring. One possibility is that consolidation and forgetting occur together for each item in memory. A second possibility is that some items decay in strength (forgetting) while others are being consolidated. Or some items consolidate rapidly and are forgotten slowly while other items consolidate slowly and are forgotten rapidly. In the latter two cases, if consolidation operates specifically to strengthen some memories while others decay, or if consolidation and decay occur differentially among items, it might be possible to detect the process of consolidation within normal memory. Specifically, if sufficient time has passed after learning a set of items, those memories that have been consolidated most strongly might be capable of being retrieved more rapidly than those that have not been consolidated so strongly.

There are two ways in which improved retrieval speed for consolidated memories might be evident. (1) For a subset of items, the fastest memory retrievals at some long delay might be even more rapid than at a shorter delay; (2) after a sufficient delay between study and test, even though reaction times (RTs) are slower overall than at a shorter delay, RTs for successful memory retrieval might distribute bimodally, reflecting a subset of rapid, consolidated memory retrievals together with slower retrievals for nonconsolidated memories. The purpose of this study was to examine reaction time distributions for successful retrieval at different times after learning. The questions of interest were (1) whether any items come to be retrieved faster as the retention delay increases, and (2) whether the reaction time distributions are noticeably bimodal.

\section{Experiment 1}

\section{PARTICIPANTS}

Sixteen staff and students at UCSD participated ( 6 men and 10 women; mean age, 26.8 years, range 21-39; mean education, 16.3 years, range 12-21).

\section{MATERIALS}

The visual stimuli were 260 line drawings of single, namable objects from the Snodgrass and
Vanderwart (1980) corpus. The stimuli were divided into four subgroups of 65 drawings each (A, $B, C$, and D), matched on name agreement (as measured by the information-theoretic $H$ statistic used by Snodgrass and Vanderwart; mean $H$ values were 0.55 or 0.56 for the four lists), image agreement (mean image agreement ratings ranged from 3.71 to 3.75 for the four lists), and familiarity (mean image familiarity ratings were 3.35 or 3.36 for the four lists). Each list contained items from all of the available categories (e.g., body part, toy, insect, etc.) in approximately equal numbers.

\section{PROCEDURE}

One hundred thirty line drawings were presented one at a time on the screen of a Macintosh Color Classic II (one drawing every 1-3 sec), with instructions to name each drawing aloud. Two lists (e.g., A and B) were presented in a mixed order. After a 10-min delay, a recognition test was given. The test consisted of one of the 65-item lists that had been presented (e.g., A), intermixed with 65 distractors from one of the 65-item nonpresented lists (e.g., C). For each item, participants decided whether the stimulus had been seen before and responded using the " $z$ " and " $/$ " keys on the computer keyboard. The keys were marked to indicate "Yes" and "No". For half of the participants, the $z$ key was marked Yes, and for the other half the / key was marked Yes. Response accuracy and latency were recorded on a Macintosh computer using MacLab software. One week later, participants returned for a second, 130-item recognition test. In the second recognition test, the items were the 65 stimuli that had been named earlier but not tested in the first recognition test (e.g., B), and 65 distractors from the remaining nonpresented list (e.g., D). The four lists were counterbalanced across participants. Half the participants received lists $\mathrm{A}$ and $\mathrm{B}$ for naming while the other half received lists $C$ and D. Of the participants who received lists $A$ and $B$, half were tested on list $A$ at the 10-min delay and list $B$ at the 1-week delay. The other half received the materials in the reverse order.

\section{ANALYSIS}

Correct Yes responses were analyzed to explore the RT distribution for items retrieved successfully from memory. The RT distribution for

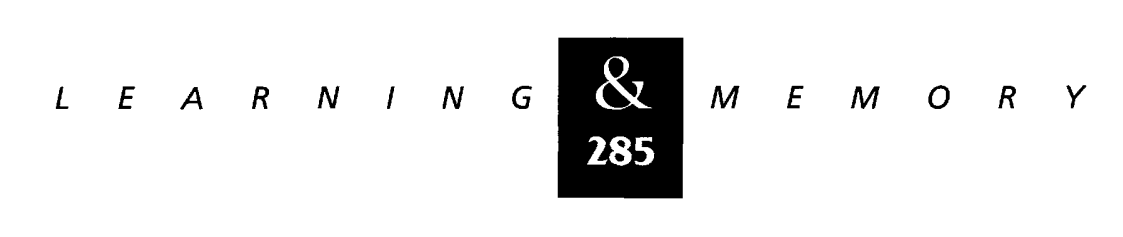


was necessitated by the smaller number of correct Yes responses obtained by subjects at the 4-month delay. The RT distributions are shown in Figure 2 together with the best fitting ex-Gaussian curves. As in experiment 1, the RT distributions observed at the 10-min and 4-month delays were fit very well by an ex-Gaussian distribution, $r^{2}=0.96$ and $r^{2}=0.91$, respectively.

The fastest $5 \%$ of RTs were significantly faster at the 10-min delay than at the 4-month delay, $t(19)=3.57, P<0.01$ (Table 2). In addition, the fastest overall RT for each individual was compared at both delays. The fastest RTs at the 10minute delay were significantly faster than the fastest RTs at the 4-month delay, $t(19)=4.38$, $P<0.01$.

\section{DISCUSSION}

Even 4 months after study, the RT distributions gave no indication of a bimodal distribution of recognition RTs. Also, there was no evidence that any memories retrieved after a 4-month delay were retrieved more rapidly than after a 10-minute delay.

The shapes of the observed RT distributions were slightly different for the 1-week and 4-month delays. The exponential $(\tau)$ parameter of the exGaussian model, which indicates how many of the responses occurred in the tail of the distribution (rather than simply being part of a normal distribution), was lower for the 4-month delay than the 1-week delay. This finding indicates that the RT distribution observed at a 1-week delay contained more correct Yes responses that were slower, relative to the observed mean and standard deviation, than did the distribution observed at a 4-month delay. This difference could have occurred if there were more weak memories at the 1-week than at the 4-month delay and if these weak memories were lost by 4 months.

\section{General Discussion}

The passage of time after learning did not reveal a discrete subset of memories that could be retrieved rapidly. First, there was no evidence that some small subset of items was actually retrieved faster after a long retention interval than after a short retention interval. Second, the RTs appeared to belong to a single distribution. There was no evidence for the emergence of a bimodal distribution of RTs, whereby some items came to be retrieved relatively more quickly than others.

The present study cannot rule out definitively the idea that RT distributions during forgetting could contain measurably bimodal features. First, it is possible that neither the 1-week nor the 4-month delay intervals provide the optimum delay at which to observe a bimodal distribution of RTs. Second, it may be that many more correct Yes responses than were obtained in the present study are needed to estimate accurately the RT distribution. The recognition memory test in experiment 1 after a 1-week delay contained 65 study items, and

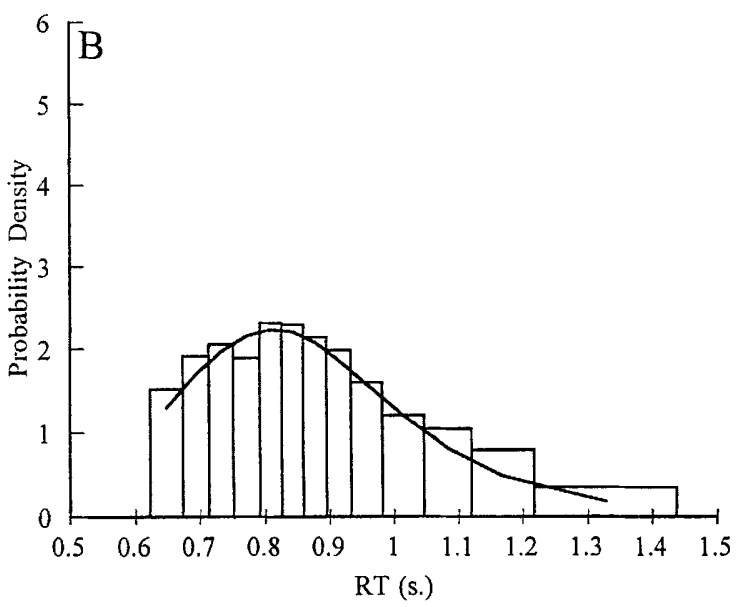

Figure 2: Average probability density functions for reaction time distributions calculated from 14 quantiles per participant. The width of each bin displays $7.14 \%$ of the data. Height $\times$ width $=0.0714$. The best fitting ex-Gaussian curve is overlaid. (A) Reaction times from the 10-min study-test delay (experiment 2). Ex-Gaussian parameters: $\tau=0.153$; $\mu=0.616 ; \sigma=0.045 ; r^{2}=0.96$. (B) RTs from the 4-month study-test delay. Ex-Gaussian parameters: $\tau=0.259 ; \mu=0.685$; $\sigma=0.098 ; r^{2}=0.91$.

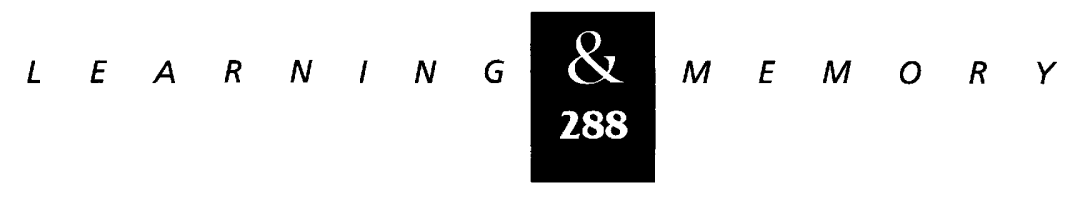


participants responded Yes correctly to an average of $59.5 \%$ of these ( -39 items). In experiment 2 , the average hit rate was only $45.6 \%$ ( -30 items).

It is important to note that our findings are based on a set of similar items learned under a similar instructional set. To observe bimodality in retrieval RTs, the items would need to have different fates (i.e., some are marked for consolidation while other items are not). Perhaps stimuli that differed more from each other would have permitted a clearer distinction between items that underwent consolidation and those that did not. For the relatively similar stimuli used in our training set, it is possible that each of the stimuli is both consolidated to a certain extent and also forgotten to a certain extent. If so, one would not expect to observe a bimodal distribution of RTs during a retrieval test.

In his classic study, Standing (1973) found high levels of recognition memory performance for pictures $(73 \%$ correct) after subjects had viewed 10,000 pictures for $5 \mathrm{sec}$ each. Accordingly, studies like the current one should be feasible using very large numbers of stimuli. The value of the current study is to show that memory tests using conventional numbers of stimuli do not reveal bimodality in the RT distributions.

One extension of the tradition of work on memory consolidation is embodied in the proposal that medial temporal lobe structures direct the gradual establishment and reorganization of memory representations in the neocortex (Alvarez and Squire 1994; Squire and Alvarez 1995). Longterm memories are gradually reorganized and stabilized so that after a period of time, these memories can be retrieved independently of the medial temporal lobe memory system (Squire and ZolaMorgan 1991). Evidence that this process occurs within long-term memory comes from the finding of temporally graded retrograde amnesia covering several years in patients with anterograde amnesia (Hodges 1984; Squire et al. 1989; Rempel-Clower et al. 1996; Schmidtke and Vollmer 1997) and from prospective studies of retrograde amnesia covering many days or weeks in experimental animals (Winocur 1990; Zola-Morgan and Squire 1990; Kim and Fanselow 1992; Cho et al. 1993; Kim et al. 1995; Cho and Kesner 1996; Wing et al. 1996). These studies indicate that medial temporal lobe structures are critically involved in the initial storage and retrieval of declarative memories. Damage to the medial temporal lobe memory system impairs both new learning and retrieval of recent (but not remote) declarative memories. After sufficient time has passed, the ability to retrieve is no longer affected by damage to the medial temporal lobe.

The present results suggest that changes in memory after learning, whether conceptualized as a simple increase in resistance to disruption or as a lengthy process of reorganization under the direction of the medial temporal lobe, may not result in any decreases in retrieval time. Rather, consolidation occurs concurrently with memory trace decay (forgetting), and the net result of the passage of time simply may be that retrieval time gradually increases.

\section{Acknowledgments}

This research was supported by the Medical Research Service of the Department of Veterans Affairs, National Institute of Mental Health grant MH24600 (L.R.S.) and MH11150 (P.J.R.). We thank N. Champagne, J. Moore, and Joyce Zouzounis for research assistance.

The publication costs of this article were defrayed in part by payment of page charges. This article must therefore be hereby marked "advertisement" in accordance with 18 USC section 1734 solely to indicate this fact.

\section{References}

Alvarez, P. and L.R. Squire. 1994. Memory consolidation and the medial temporal lobe: A simple network model. Proc. Natl. Acad. Sci. 91: 7041-7045.

Burnham, W.H. 1903. Retroactive amnesia: Illustrative cases and a tentative explanation. Am. J. Psychol. 14: 382-396.

Cho, Y.H. and R.P. Kesner. 1996. Involvement of entorhinal cortex or parietal cortex in long-term spatial discrimination memory in rats: Retrograde amnesia. Behav. Neurosci. 110: $436-442$.

Cho, Y.H., D. Beracochea, and R. Jaffard. 1993. Extended temporal gradient for the retrograde and anterograde amnesia produced by ibotenate entorhinal cortex lesions in mice. J. Neurosci. 13: 1759-1766.

Glickman, S.W. 1961. Perseverative neural processes and consolidation of the memory trace. Psychol. Bull. 58: $218-233$.

Heathcote, A., S.J. Popiel, and D.J.K. Mewhort. 1991. Analysis of response time distributions: An example using the Stroop task. Psychol. Bull. 102: 230-347.

Hodges, J.R. 1984. Retrograde amnesia. In: Handbook of memory disorders (ed. A. Baddeley, B.A. Wilson, and F. Watts), pp. 81-107. John Wiley, New York, NY.

Kim, J.J. and M.S. Fanselow. 1992. Modality-specific retrograde amnesia of fear. Science 256: 675-677.

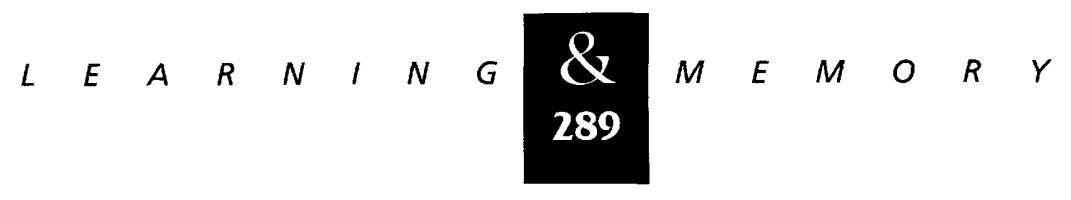


Kim, J.J., R.E. Clark, and R.F. Thompson. 1995. Hippocampectomy impairs the memory of recently, but not remotely acquired trace eyeblink conditioned responses. Behav. Neurosci. 109: 195-203.

Luce, R.D. 1986. Response times: Their role in inferring elementary mental organization. Oxford University Press, New York, NY.

McDougall, W.R. 1901. Experimentelle Beitrage zur Lehre vom Gedachtniss [Experimental contributions to the theory of memoryl Mind 10: 388-394.

McGaugh, J.L. 1989. Involvement of hormonal and neuromodulatory systems in the regulation of memory storage. Annu. Rev. Neurosci. 12: 255-288.

McGaugh, J.L. and M.J. Herz. 1972. Memory consolidation. Albion, San Francisco, CA.

Press, W.H., S.A. Teukolsky, W.T. Vetterling, and B.P. Flannery. 1992. Numerical recipes in C: The art of scientific computing. Cambridge University Press, Cambridge, UK.

Ratcliff, R. 1978. A theory of memory retrieval. Psychol. Rev. 85: 59-108.

1979. Group reaction time statistics and an analysis of distribution statistics. Psychol. Bull. 86: 446-461.

Rempel-Clower, N.L., S.M. Zola, L.R. Squire, and D.G. Amaral. 1996. Three cases of enduring memory impairment following bilateral damage limited to the hippocampal formation. J. Neurosci. 16: 5233-5255.

Russell, W.R. and P.W. Nathan. 1946. Traumatic amnesia. Brain 69: 280-300.

Schmidtke, K. and H. Vollmer. 1997. Retrograde amnesia: A study of its relation to anterograde amnesia and semantic deficits. Neuropsychologia 35: 505-518.

Snodgrass, J.G. and M. Vanderwart. 1980. A standardized set of 260 pictures: Norms for name agreement, image agreement, familiarity, and visual complexity. J. Exper. Psychol. Hum. Learn. Mem. 6: 174 215.

Squire, L.R. and P. Alvarez. 1995. Retrograde amnesia and memory consolidation: A neurobiological perspective. Curr. Opin. Neurobiol. 5: 169-177.

Squire, L.R. and C.W. Spanis. 1984. Long gradient of retrograde amnesia in mice: Continuity with the findings in humans. Behav. Neurosci. 98: 345-348.

Squire, L.R. and S. Zola-Morgan. 1991. The medial temporal lobe memory system. Science 253: 1380-1386.

Squire, L.R., P.C. Slater, and P.M. Chace. 1975. Retrograde amnesia: Temporal gradient in very long-term memory following electroconvulsive therapy. Science 187: 77-79.

Squire, L.R., F. Haist, and A.P. Shimamura. 1989. The neurology of memory: Quantitative assessment of retrograde amnesia in two groups of amnesic patients. J. Neurosci. 9: 828-839.

Standing, L. 1973. Learning 10,00 pictures. Q. J. Exp. Psychol. 25: 207-222.

Vincent, S.B. 1912. The function of the vibrissae in the behavior of the white rat. Behav. Monogr. 1: (5).

Wiig, K.A., L.N. Cooper, and M.R. Bear. 1996. Temporally graded retrograde amnesia following separate and combined lesions of the perirhinal cortex and fornix in the rat. Learn. Mem. 3: 313-325.

Winocur, G. 1990. Anterograde and retrograde amnesia in rats with dorsal hippocampal or dorsomedial thalamic lesions. Behav. Brain Res. 38: 145.

Zola-Morgan, S. and L.R. Squire. 1990. The primate hippocampal formation: Evidence for a time-limited role in memory storage. Science 250: 288-290.

Received June 19, 1997; accepted in revised form August 15, 1997. 


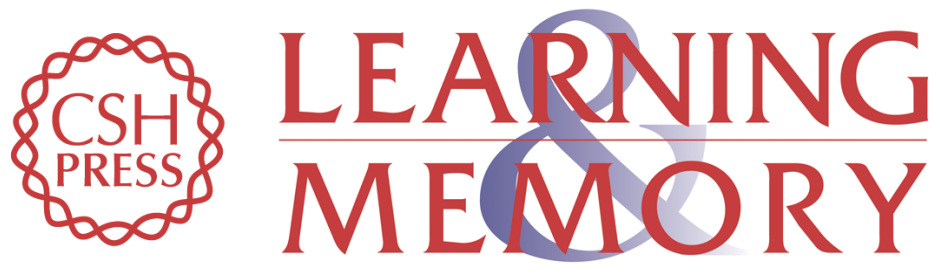

\section{Reaction time distributions across normal forgetting: searching for markers of memory consolidation.}

P J Reber, P Alvarez and L R Squire

Learn. Mem. 1997, 4:

Access the most recent version at doi:10.1101//m.4.3.284

References This article cites 7 articles, 3 of which can be accessed free at: http://learnmem.cshlp.org/content/4/3/284.full.html\#ref-list-1

License

Email Alerting Receive free email alerts when new articles cite this article - sign up in the box at the Service top right corner of the article or click here. 